\title{
TROPICAL PARAPLEGIA: A CASE OF TRANSVERSE MYELITIS, PROBABLY CAUSED BY SCHISTOSOMIASIS MANSONI
}

\author{
By G. M. Pool, M.D. \\ Zuiderziekenhuis, Rotterdam, The Netherlands
}

Abstract. In tropical regions transverse myelitis may be caused by involvement with schistosoma or the eggs of this organism.

Although 200 million people seem to be infected with this disease, involvement of the spinal cord is rare. A case of a 15-year-old boy is described and some literature reviewed.

Key words: Schistosomiasis transverse myelitis case report; Selective angiography.

\section{Introduction}

IN tropical regions one of the causes of a paraplegia may be involvement of the spinal cord with schistosoma. Schistosomiasis is the name given to a group of diseases caused by trematodes which is a bisexual parasite of the genus Schistosoma, for instance, S. haematobium, S. mansoni, S. japonicum.

Theodor Bilharz was the first to discover the parasites in the mesenteric veins of an autopsied case in Kasr-el-Aini Hospital in Cairo, in I85I. In I858 Weiland proposed the term 'schistosoma' for the parasite because of the gynaecophoric canal which simulated a longitudinal split (schis, fissile; soma, body). At present, the term 'bilharziasis' is used in reference to the disease, and 'schistosoma' in reference to the ova or parasites.

People of all ages are susceptible to infection, the peak is between 7 and 15 years. It is possible to build up a resistance against schistosomiasis and acquired immunity has also been proved. In 1965 the World Health Organisation estimated that I80-200 million persons were infected throughout the world. In Egypt alone at least 37 per cent of the population are said to be infected.

Schistosomiasis or bilharziasis is a disease caused by an invasion through the skin, namely by way of active muscular action and glandular secretion of schistomules the horny layer of the skin is penetrated within $15 \mathrm{~min}$ and by way of the lymphatic system in 4-5 days the circulatory system is reached.

In the liver the schistosomes mature and couple before migrating through the portal system against the blood stream into the mesenteric or vesical veins to commence egg-laying.

The ova migrate through the thinner blood vessels in great quantities and cause reactions in the organs that they reach. Ova may reach any organ of the body. Eventually part of the eggs escape from the body via the stool and urine to start a new life cycle in another host, mostly a snail.

\section{Schistosomiasis of the Spinal Cord}

This is a rare complication. Herskowitz (1972) collected I04 cases of schistosomiasis of the central nervous system of which 25 were limited to the spinal

Address for offprints: Dr G. M. Pool, Groene Hilledijk 315, 3075 EA Rotterdam, The Netherlands. 
cord. Ghaly and El-Banhawy (1973) described various types of schistosomiasis of the spinal cord, including:

I. Inflammatory granulomatous form. This is the commonest type, usually a space-occupying mass in the centre of the conus medullaris is found, compressing adjacent nervous tissue. The mass is composed of multiple units of microtubercles showing the typical schistosomal reaction. Ghaly and El-Banhawy described six cases of this type which they surgically verified.

2. Acute necrotising myelitis. This is less frequent and mainly secondary to a necrotising vasculitis produced by ova blocking the blood vessels to set up an intense vascular reaction. This mainly occurs with the mansoni and the haematobium type. The japonicum type of schistosomiasis rarely seems to affect the spinal cord.

3. Deposition of ova in the cord. In this case there is no obvious reaction and the nervous tissue looks normal. According to Ghaly and El-Banhawy more cases of this variety would be found if the spinal cord were examined as a postmortem routine in case of schistosoma infection.

Many questions have still to be solved as to how the worms derive from the schistosoma and how their ova reach the spinal cord and inflict their damage. In the literature there are already sufficient descriptions and proven cases to repeat the warning of several authors that schistosomiasis must be borne in mind when considering obscure spinal cord lesions in those who may have been exposed to a schistosoma infection.

The commonest place of spinal cord involvement is in the low thoracic, high lumbar region. This predilection is thought to be due to the so-called free anastomosis between the pelvic veins and the valveless vertebral venous plexus. Schistosomas from the bladder and bowel may find access to these veins, for instance when the inter-abdominal pressure is raised.

El-Banhawy (I97I; El-Banhawy et al., I972) has suggested another possible explanation, namely arterial embolisation. In this case the ova reach the cord via the 'arteria radicalis magna anterior' as described by Adamkiewicz in I88I. This artery is the largest anterior feeder in the upper lumbar portion of the cord, it occurs unilaterally and is usually on the left side. This would explain the sites of predilection. Neves et al. (1973) suggests immuni-allergic reactions from products derived from dead worms and their eggs.

\section{Case Report}

A I 5-year-old boy became acutely ill with abdominal pains, diarrhoea and moderate fever in Paramaribo, Surinam. He was admitted to a hospital, and within a week he developed a flaccid paralysis of both legs with total sensory loss below Tro. He quickly developed pressure sores on both hips. He was seen by a consultant neurosurgeon from Holland and it was decided to transfer him to Leiden University Hospital, for further investigation, since his parents intended to emigrate to The Netherlands. At Leiden a normal myelogram was found and a strongly positive serological reaction on schistosomiasis (titre $\mathrm{I} / 256$ ) with ova of schistosoma in his stool. His case was diagnosed as a transverse myelitis probably caused by schistosomiasis mansoni.

He was subsequently treated with Ambilhar (R), but without any improvement of his paraplegia. After that the boy was transferred to my unit. In the literature on spinal cord involvement with schistosomiasis, pressure sores at the hip-region are recorded more than once, although the patients are usually only boys between IO and 20 years of age.

In my patient the pressure sores did not react at all to the usual treatment and 
therefore the trochanter had to be removed on both sides and the wounds closed with rotation flaps. These operations were successful although our patient also had an anaemia with a sickle cell trait.

Being confronted with a rare complication of a disease common in tropical countries and because of the theory of arterial embolisation of worms and ova (El-Banhawy 197I; El-Banhawy et al., I 972) it was decided to perform a selective spinal angiography (Fig. I). Adamkiewicz's artery was found to have its origin from the tenth intercostal on the left side. After the injection of contrast selective in that intercostal it was found that Adamkiewicz's artery divided at the level of $\mathrm{T}_{9}$ in an ascending and descending branch of the anterior medium longitudinal artery. The arterial aspect of our patient at the low thoracic, high lumbar region seemed normal. Immediately after injecting the contrast we observed flexion and extension movements of both legs and arms, resembling an epileptic seizure, although he was in pentothal narcosis. There was a reaction of his cord to the stimulus of the contrast injection.

\section{Discussion}

No abnormality was found in our patient either with the myelogram or with the selective angiogram, but there was the strongly positive schistosomal complement fixation test and ova of schistosoma in his stool.

According to Graham et al. (1962), Neves et al. (1973) and El-Banhawy (I97I; El-Banhawy et al., I972) a strongly positive fixation test should be regarded as specific for spinal cord involvement in patients with a transverse myelitis. When considering how our patient could have acquired his transverse myelitis

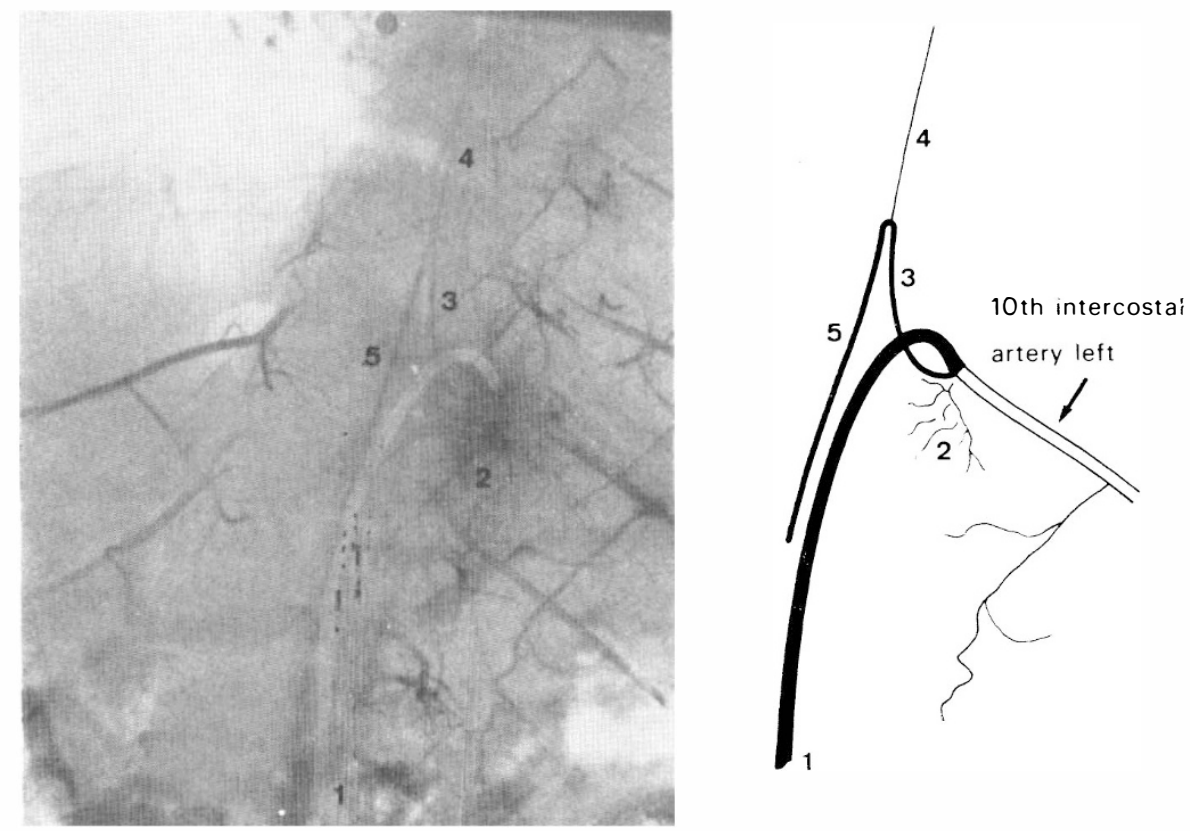
1: catheter
2: muscle-arteries
3: artery of Adamkıewicz

\begin{abstract}
4: ascending part of the anterior spinal artery
5: descending part of the anterıor spinal artery $4+5$ : the anterior spinal artery
\end{abstract}

FIG. I 
reaction from a schistosomal infection with a normal myelogram and a normal selective angiogram one must remember the pioneer work of Batson (1940) and Dommisse (1975) who demonstrated the passage of injection material from the pelvis to the brain along venous channels of the vertebral column.

In our patient it is possible that ova reached the cord from the pelvis with the venous stream and gave a local vascular immuno-allergic reaction (Neves, I973), resulting in his transverse myelitis, which, however, left no signs on the angiogram. In this respect Wakefield et al. (1962) and Lechtenberg and Vaida (I977) suggest to treat patients with a combination of chemotherapy and steroids when the spinal cord is involved and to start with this treatment as soon as possible with $80 \mathrm{mg}$ or more Prednisone daily.

\section{The Title}

For this communication 'Tropical Paraplegia' was chosen as a title, not to add still another diagnosis to the large number of possibilities which already exist, but to draw attention to the fact that schistosomiasis may also be the cause of a transverse myelitis, especially in tropical regions.

\section{SUMMARY}

A case of a transverse myelitis probably caused by schistosomiasis mansoni is described and some literature reviewed. The finding of a normal selective angiogram and normal myelogram is discussed, and a therapy possibility for certain cases suggested.

\section{RÉSUMÉ}

Une observation de paraplegie chez bilharziens est rapportée.

Discussion d'une angiogramme selective normale et d'une myelogramme normale.

Proposition d'une therapie pour des cas certains.

\section{ZUSAMMENFASSUNG}

Ein Fall einer Myelitis transversa, wahrscheinlich verursacht von Bilharziasis, wird beschrieben.

Der Befund eines normalen Myelogrammes und eines normalen selektieven Angiogrammes wird besprochen.

Eine Therapie-Möglichkeit wird vorgeschlagen.

Acknowledgements. I wish to thank Dr Tolhurst and Dr Wythof, plastic surgeon, and Dr Kho Swan Nio, radiologist, for their invaluable help.

\section{REFERENCES}

Abbott, P. H. \& Spencer, H. (1953). Transverse myelitis due to ova of schistosoma mansoni. Trans. Roy. Soc. Trop. Med. and Hyg. 47, $22 \mathrm{I}$.

Batson, O. V. (1940). Ann. Surg. I12, 138.

Dommisse, G. F. (1975). Arteries and Veins of the Human Spinal Cord from Birth. Churchill Livingstone, Edinburgh.

El-Banhawy, A. (I97I). Bilharziasis of the spinal cord. Proceedings of the 4th European Congress Neurosurgery, Prague, p. 757.

El-Banhawy, A., ElWIN, O. \& TAHER, Y. (1972). Bilharzial granuloma of the conus medullaris and cauda equina. Paraplegia, I0, 172. 
Ghaly, A. F. \& El-Banhawy, A. (1973). Schistosomiasis of the spinal cord. F. Path. II I, 57.

HersKowitz, A. (I972). Spinal cord involvement with schistosoma mansoni. F. Neurosurg. 36, 494.

Lechtenberg, R. \& VAidA, G. A. (1977). Schistosomiasis of the spinal cord. Neurology, 27, 55-59.

Neves, J., Marinho, R. P., de Araujo, P. K. \& Raso, P. (1973). Spinal cord complications of acute schistosomiasis mansoni. Trans. Roy. Soc. Trop. Med. Hyg., 67, 782.

Wakefield, G. S., Carroll, J. D. \& Speed, D. E. (1962). Schistosomiasis of the spinal cord, Brain, 85, 535. 